DOI 10.37882/2500-3682.2021.02.23

\title{
РОЛЬ БИБЛИОТЕКИ НОВОГО ТИПА В ПРОЦЕССЕ АККУЛЬТУРАЦИИ В РЕГИОНАЛЬНОМ КУЛЬТУРНОМ ПРОСТРАНСТВЕ
}

\section{THE ROLE OF A NEW TYPE OF LIBRARY IN THE PROCESS OF ACCULTURATION IN THE REGIONAL CULTURAL SPACE \\ A. Plyakhotko E. Akulich}

Summary: This article reveals the regional specifics of the socio-cultural role of a new type of library in the process of mutual influence of cultures. The author substantiates the idea that in the conditions of a new type of library, the activity and vital activity of a person, moral and creative, is activated. It is established that the universality of a new type of library consists in the acculturation of a person in the conditions of a regional cultural environment, in the possibility of a person's entry into culture, assimilation of cultural and behavioral norms and values of national culture.

Keywords: integration, acculturation, telecommunication technologies, a new type of library, mutual influence of cultures, educational projects, cultural practices.

\author{
Пляхотко Александр Сергеевич \\ Преподаватель, Тюменский государственный \\ институт культуры \\ sanek_tyumen@mail.ru \\ Акулич Евгений Михайлович \\ Д.с.н., профессор, Тюменский государственный \\ институт культуры \\ akulich.em@gmail.com
}

Аннотация: В данной статье раскрывается региональная специфика социокультурной роли библиотеки нового типа в процессе взаимовлияния культур. Обосновывается идея о том, что в условиях библиотеки нового типа активизируется активность и жизнедеятельность личности, нравственной и творческой. Установлено, что универсальность библиотеки нового типа заключается в аккультурации человека в условиях региональной культурной среды, в возможности вхождения человека в культуру, усвоении им культурных и поведенческих норм и ценностей национальной культуры.

Ключевые слова: интеграция, аккультурация, телекоммуникационные технологии, библиотека нового типа, взаимовлияние культур, просветительские проекты, культурные практики.
$\mathrm{B}$ последнее время трудно недооценивать роль интеграционных процессов в экономической, социальной и образовательной сферах. Со второй половины XX в. объём накапливаемой информации и интенсивность обменных потоков стали нарастать лавинообразно. Информационная революция стремительно меняет мировые коммуникационные процессы. Человечеству предоставляются принципиально новые решения и возможности во всех сферах его жизнедеятельности, но при этом информационная революция актуализирует совершенно новые проблемы. Успешность разрешения таких проблем является немаловажным фактором, влияющим на развитие глобального информационного общества. Процессы взаимовлияния культур, связанные с восприятием одним народом полностью или частично культуры другого народа, как правило, более развитого, принято определять как процессы аккультурации. В основе аккультурации лежит коммуникативный процесс. Для того чтобы выявить роль и место современной библиотеки в процессе межкультурной коммуникации, целесообразно углубиться в исторический аспект, сфокусировав внимание на системе социокультурных практик взаимовлияния и взаимодополнения культур.

Как отмечает известный американский антрополог
Ф. Боас, последние коллекции фольклора американских индейцев показывают, что аборигены североамериканского континента ассимилировали немало европейского материала. Многие сюжеты, обнаруженные у индейцев, оказываются при ближайшем рассмотрении версиями хорошо известных европейских сказок [3, с. 172]. Проведя масштабную исследовательскую работу, Боас выявил, что первые французские колонисты принесли в Америку собственные верования и сказки. Всюду, где побывали французские купцы, встречаются сказки о Семиглавце и Джоне-Медведе. Испанские сказки также распространились от Калифорнии, Аризоны, Нью-Мексико и Техаса к югу континента, охватывая все районы контактов испанцев с аборигенами. Большое распространение получили также сказки на библейские темы - нравоучительные басни, предназначенные для духовного назидания. $\mathrm{K}$ ним принадлежит ряд сюжетов древнегреческого поэтабаснописца Эзопа. Отмечается, что сказки этой группы видоизменялись очень мало. Многие североамериканские сказки о потопе также явно связаны с библейскими источниками. При этом есть немало и туземных сказок такого рода. Обе группы подверглись очень глубокой взаимоассимиляции, поэтому библейский сюжет в ряде случаев трудно отличить от аборигенного. Таким образом, вполне очевидно, что романские источники соста- 
вили значительную часть аборигенного предания Америки и что в некоторых случаях в туземном фольклоре обнаруживаются даже стилистические черты романоязычной сказочной традиции [3, с. 179].

Процессы аккультурации также заметно прослеживаются при анализе социокультурной революции провинциальных российских городов, расположенных к востоку от Уральских гор, в районе, который достаточно условно определяется как Северное Зауралье, происходившей в период конца XVIII - начала XX в. Как отмечает исследователь М.Ф. Ершов, города Северного Зауралья близки по своему происхождению. Наличие общей исторической памяти сближало население, содействовало выработке единых аксиологических установок и формированию необходимых образов городов [6, с. 44]. С освоением территории Зауралья происходит развитие торговли, требующей от местного населения коммуникации с иногородними и даже иноязычными торговцами, а, следовательно, координации усилий местных жителей. Приезжие, не зная специфики конкретного населённого пункта, могли провоцировать те или иные конфликты. Это было связанно с особенностями межкультурной коммуникации, подразумевающей связи и общение между представителями различных культур. Таким образом, происходит переход от стабильного существования к социальной динамике. Коммуникативные функции начинают выполнять различные социальные институты, в первую очередь, система образования. Неразвитость школьного образования восполнялась литературными журналами. В центральной прессе стало появляться всё больше краеведческих заметок. При этом передача информации часто была двусторонней. Так, например, публикуя в столичном издании сведения о местной провинциальной действительности, автор тем самым включал в систему межкультурных коммуникаций большой России себя и своё социальное окружение [6, с. 48].

Особую историческую роль в формировании общественной и культурной жизни Сибири сыграли сосланные декабристы. Так, 121 декабрист был приговорен к высылке в Сибирь на каторжные работы. Как отмечается в исторических документах, представленных в фонде Президентской библиотеки, измученные физическим трудом, они всё же находили время и для удовлетворения своих умственных запросов: читали друг другу целые курсы различных наук, поэты писали стихи, художники рисовали, музыкальные люди организовывали хор и т.д. Бедное рабочее население мест ссылки видело в декабристах мучеников за народное дело, за волю и не могло не быть им благодарно за широкую благотворительность и помощь личным трудом и советами. Сибирская интеллигенция ценила в декабристах большое образование, либеральные убеждения, независимость и честность [8, с. 8].
Длительная практика в огородничестве в Чите и в Петровском создала из многих декабристов опытных огородников. Свой опыт они принесли в поселения, где жили, и охотно делились им с крестьянами. Они выписывали из родных мест семена, уделяли часть их крестьянам, устраивали парники, делали опыты с различными овощами и следили за сельско-хозяйственной литературой. Не только декабристы, но и жёны их часто с увлечением отдавались огородничеству. Наряду с этим декабристы старались привить местному крестьянству интерес к новым для них промыслам. Декабристы охотно делились своими познаниями с окружающими их. Они давали различные практические советы и оказывали медицинскую помощь, наконец, заботились об их просвещении. [2, с. 44]. Также декабристы занимались научным изучением Сибирского края, собирали коллекции сибирской флоры и фауны, коллективно вели метеорологические наблюдения, которые они передавали в Берлинскую Академию Наук. Отдельные декабристы принимали участие в научных экспедициях. Таким образом, декабристы и их жёны внесли неоценимый вклад в исследование Сибири, оказали существенное влияние на культуру и образование.

В настоящее время процессы аккультурации тесно связаны с современными информационно-техническими возможностями передачи информации. Благодаря современным телекоммуникационным технологиям культурное наследие было переведено в цифровую форму, тем самым обеспечив его сохранение. В данных технологиях межкультурная коммуникация представляет собой механизм обмена информацией в глобальных информационных системах. С одной стороны такие технологии, являясь инновационной формой коммуникации, раскрывают обществу невиданные ранее возможности, с другой - могут являться инструментом информационной войны и привести к кризису культуры, разрушая её ценностные основания. Мы согласны с утверждением канадского философа М. Маклюэна, который отмечал, что решение человека модифицировать используемую им визуальную технологию посредством обращения к технологии электрической неизбежно приводит к трансформации индивидуализма. Предъявлять по этому поводу какие-либо моральные претензии и жалобы равносильно тому, что ругать циркулярную пилу за то, что она отрезала пальцы [9, с. 280]. Таким образом, необходимо системное изучение влияния инновационных форм коммуникации как на процессы аккультурации, так и на всю культуру, являющую собой систему исторически развивающихся надбиологических программ человеческой жизнедеятельности, обеспечивающих воспроизводство и изменение социальной жизни во всех ее основных проявлениях [11, с. 11]. Элементом данной системы выступают библиотечные учреждения. Библиотеки являются одним из древнейших, в то же время самых уникальных культурных институтов человечества, поэтому 
в современном культурном пространстве они всё чаще становятся предметом междисциплинарных исследований и по достоинству считаются центрами межкультурной коммуникации. Мы разделяем позицию исследователя Е.Ю. Гениевой, которая отмечает, что в последнее время происходит преобразование библиотек в центры взаимодействия культур, формирующие поликультурную личность, способную адекватно реагировать на вызовы современного мира, успешно преодолевать барьеры понимания и культурные стереотипы [4, с. 8].

Особенностью социокультурного пространства информационного общества, даже его начальной фазы, является такая ситуация информационного взрыва, когда объём информации даже по узкой профессиональной сфере деятельности превышает возможности человека её воспринимать и анализировать в полном объёме. Нарастающая сила потока информационного обмена между людьми породила новый тuп культуры, в которой всё подчинено необходимости классификации, унификации с целью наибольшей компрессии и повышения эффективности при передаче от человека к человеку [7, с. 52]. Любые технические новшества и идеи становятся эффективными в социальном плане в тех случаях, когда они оказываются неотъемлемой частью общей культуры. Это в значительной мере меняет представления, взгляды, поведение, образ жизни и мышление современного человека и предъявляет к нему новые требования. Главным из них является овладение информационной культурой. Возникает потребность осознания информационной культуры как важнейшего показателя развития информационного общества и становления нового характера взаимодействия человека и окружающей среды [1, с. 123]. Таким образом, уровень развития информационного общества определяется не только уровнем становления технической сферы, но и уровнем информационной культуры его членов.

Применение новых технологий существенно изменило современные библиотечные процессы и способствовало повышению уровня обслуживания читателей, что стало причиной появления новых форм и методов работы, а также создало условия, наряду с традиционной библиотечной деятельностью, для широкой пропаганды электронного библиотечного дела. Интенсивное проникновение информационно-телекоммуникационных технологий в библиотечную деятельность привело к появлению в России библиотеки нового типа - современного библиотечного учреждения, в котором активно применяются современные технологии в обслуживании пользователей, направленные на повышение эффективности работы с информацией. Такие библиотеки не являются застывшим образованием, а представляют собой динамичный и растущий организм. 27 мая 2009 г. в Санкт-Петербурге открылась Президентская библиотека им. Б.Н. Ельцина. Она функционирует как общегосу- дарственное электронное хранилище цифровых копий важнейших документов по истории, теории и практике российской государственности, а также русскому языку и имеет статус национальной библиотеки России. Оцифрованные материалы имеют неоспоримое преимущество, поскольку, как утверждает Е.Б. Грузнова, электронный документ может быть предоставлен в любом месте, в любой момент времени и одновременно нескольким пользователям [5, с. 45]. Именно поэтому при создании Президентской библиотеки было предусмотрено открытие её филиалов и удалённых читальных залов во всех регионах страны. В настоящее время функционирует более тысячи центров удалённого доступа во всех 85 субъектах Российской Федерации, а также за рубежом. По состоянию на начало 2020 г. фонд библиотеки насчитывает более 850 тысяч электронных копий книжных и периодических изданий, фотографий, архивных документов, аудио- и видеозаписей, научно-просветительских фильмов, видеолекций, вебинаров и других материалов.

Просветительские проекты Президентской библиотеки ориентированы на использование мультимедиаформ, которые доступны через Интернет для всех заинтересованных пользователей. Эти проекты основываются на ресурсах Президентской библиотеки и стимулируют пользователей обращаться к ее фондам. Кроме того, они ориентированы на активное взаимодействие с вузами и школами страны, реализацию совместных образовательных проектов.

С 2011 г. учреждение проводит видеолекторий «Знание о России», тематика которого связана с юбилейными датами российской истории. Для участия в проекте приглашаются яркие и интересные лекторы, слушатели из числа студентов и школьников. Один из лекторов выступает в режиме видео-конференц-связи и представляет «региональный» взгляд на тот или иной вопрос. Также ряд аудиторий подключается удалённо и принимает участие в обсуждении лекций. Ведется прямая трансляция видеолектория в Интернете, что позволяет существенно расширить число участников.

Наиболее масштабным образовательным проектом Президентской библиотеки является олимпиада «Россия в электронном мире». Она адресована подрастающему поколению и нацелена на привлечение внимания к вопросам государственности, нравственным и культурным ценностям, на воспитание гражданственно-патриотических чувств. Олимпиада призвана выявить молодые таланты в области изучения гуманитарных дисциплин и популяризовать гуманитарное знание среди молодежи. Жюри олимпиады формируется из авторитетных ученых и преподавателей. Олимпиада проходит в три этапа: первый и второй - дистанционно, третий - в Президентской библиотеке и ее региональных представительствах. На последнем этапе участники в том числе полу- 
чают доступ к фондам электронного читального зала: выполняют поиск необходимой литературы по теме и на ее основе пишут небольшое сочинение. В 2018/2019 учебном году общее количество участников олимпиады составило 6080 человек.

23 мая 2011 г. на базе Тюменской областной научной библиотеки им. Д.И. Менделеева состоялось официальное открытие Тюменского филиала Президентской библиотеки им. Б.Н. Ельцина, который осуществляет тесное сотрудничество с системой образования Тюменской области.

Одним из проектов филиала является развитие с 2012 года сетевого партнёрства с Тюменским высшим военно-инженерным командным училищем имени маршала инженерных войск А.И. Прошлякова (ТВВИКУ), дислоцированным в городе Тюмени. Библиотечными специалистами было проведено обучение по работе с ресурсами Президентской библиотеки более ста преподавателей и более трёх тысяч курсантов. Бо́льшая часть прошедших обучение завели личные учётные записи для входа в электронный читальный зал (Эч3) Президентской библиотеки. Курсанты старших курсов, реализуя свой творческий потенциал, получили возможность сопровождать процесс индивидуального образования курсантов ТВВИКУ в качестве тьютора, обучая курсантов младших курсов работе с ресурсами библиотеки. В настоящее время в ТВВИКУ проходят обучение военнослужащие из 34-х иностранных государств ближнего и дальнего зарубежья. В училище на постоянной основе функционирует центр удалённого доступа к Эч3, благодаря чему у преподавателей и студентов данного учебного заведения есть полный доступ ко всему контенту Президентской библиотеки.

С ноября 2013 года действует соглашение о сотрудничестве между ГАУ Северного Зауралья и Президентской библиотекой. ГАУ Северного Зауралья один из старейших вузов региона, преемник Александровского реального училища и Тюменского сельскохозяйственного техникума. Вуз имеет богатую историю, традиции и устоявшуюся систему учебно-образовательного и научного процесса. Государственный аграрный университет - это не только учебное заведение, но и научный центр, в состав которого входят различные структуры: научные и инженерные лаборатории, исследовательские центры и др. Одно из направлений совместной деятельности ГАУ Северного Зауралья и Президентской библиотеки, - это продвижение научных разработок ученых университета. В фондах университетской библиотеки хранится более двухсот ценных научных работ: 60 монографий, более 30 сборников научных трудов, выпуски журнала Вестник сельскохозяйственной академии за двадцать лет. Научный интерес для исследователей представляют монографии классиков агрономии: Каретина Л.Н., Мер- шаловой А., физиологии: Юдичева, биологов-ветеринаров Ямова В.3., Сивкова Г.С., Солопова Н.В., зооинженера Головина В.А., а также тех, кто продолжает начатое ими дело: профессоров Абрамова Н.В., Федоткина В.А., Иваненко А.С, Лящева А.А. и др. Информационное поле Президентской библиотеки позволяет при передаче трудов тюменских ученых познакомить с ними научное сообщество не только России, но и всего мира. С другой стороны, тюменские ученые сельскохозяйственного и экономического направления, могут найти в фондах Президентской библиотеки интереснейший материал для своих исследований, способствующих превращению информации в знание.

Тюменским филиалом Президентской библиотеки им. Б.Н. Ельцина совместно с ГАУ Северного Зауралья был выработан просветительский проект «Агроцивилизация», который реализуется в Тюменской области с 2015 года. Для решения цели проекта - поднятия престижа сельского образа жизни и аграрных профессий были разработаны специальные инструменты: уроки, семинары, квест-игры, конференции и прочие мероприятия, способствующие формированию аграрного сознания у детей и подростков в возрасте 7-18 лет. Наилучшей формой реализации было признано социальное волонтерство. Волонтерами-тьюторами выступили студенты аграрного вуза, которые прошли обучение по основам детской психологии, педагогики, методике обучения и работе с ресурсами Президентской библиотеки. Тьюторы работали в средних школах, обучая детей по двум направлениям - уроки-лекции «Жизнь села и аграрные профессии» и уроки семинары «Учусь работать в президентской библиотеке». С 2016 года включились наставники и тьюторы в подготовку школьников к школьной научной конференции. Конференции показали неподдельный интерес сельских детей к аграрным проблемам и желание эти проблемы решать.

В 2017 году было заключено соглашение между Тюменским институтом повышения квалификации сотрудников МВД России (ТИПК МВД России) и Президентской библиотекой им. Б.Н. Ельцина о стратегическом партнёрстве в деле формирования единого информационного пространства в области истории, теории и практики российской государственности [10, с. 72]. ТИПК МВД России является полнофункциональным специализированным учебным комплексом, отвечающим всем современным требованиям дополнительного профессионального образования и осуществляющим обучение сотрудников подразделений и служб территориальных органов МВД России 9 федеральных округов и 85 субъектов Российской Федерации. За 3 года сотрудничества сотрудниками Тюменского филиала Президентской библиотеки было проведено более 40 практикоориентированных занятий с работниками правоохранительных органов со всей Российской Федерации. Более 400 сотрудников по- 
лиции ознакомились с возможностями Президентской библиотеки и также завели личные учётные записи для входа в электронный читальный зал для того, чтобы работать с её ресурсом непосредственно по месту проживания.

Опыт функционирования библиотеки нового типа на примере Президентской библиотеки им. Б.Н. Ельцина и её Тюменского филиала демонстрирует эффективность современных электронных библиотек, обеспечивающих доступ к информационным ресурсам в удалённом режиме на основе телекоммуникационных технологий. Очень значимым для проведения научных исследований гуманитарного цикла является доступ к архивным материалам, который обеспечивается использованием поисковой системы библиотеки. Культурные практики, разрабатываемые и реализуемые Президентской библиотекой совместно с организациями-партнёрами и направленные, в первую очередь, на учащуюся молодёжь, носят интегративный, комплексный характер. Благодаря им молодёжь осваивает социокультурные нормы и образцы деятельности, получает опыт работы с электронным ресурсом в доступном формате. Участники данных мероприятий имеют возможность трансляции полученных знаний и навыков работы с уникальным ресурсом не только на территории Российской Федерации, но и за её пределами. Таким образом, мы полагаем, что роль библиотеки нового типа в процессе взаимовлияния культур является колоссальной, поскольку современная библиотека не только обеспечивает сохранение культурного наследия, но и выступает его активным транслятором, объединяя народы России и всего мира.

\section{ЛИТЕРАТУРА}

1. Абдуллаева, А.Т. Электронные библиотеки в формировании информационной культуры / А.Т. Абдуллаева // Научные и организационно-технологические основы интеграции цифровых информационных ресурсов: [сборник научных трудов] / Президент. б-ка им. Б. Н. Ельцина. Вып. 4. - Санкт-Петербург: ФГБУ «Президентская библиотека имени Б. Н. Ельцина», 2013. - 378, [1] с.: ил. - С. 120-128.

2. Базилевич, В.М. Декабристы: Очерки: 1-3. - Киев: Типография Киевского Политехн. ин-та, 1926. - 48 с.

3. Боас, Ф. Романский фольклор у американских индейцев / Ф. Боас // Антология исследований культуры. Отражения культуры / сост. Л. А. Мостова. Москва: Петроглиф, 2011. - 421, [1] с. - С. 172-180.

4. Гениева, Е.Ю. Библиотека как центр межкультурной коммуникации / Е.Ю. Гениева. - М.: «Российская политическая энциклопедия» (РОССПэН), 2008. 208 c.

5. Грузнова, Е.Б. Национальный электронный ресурс Президентской библиотеки: основные подходы к формированию / Е.Б. Грузнова // Электронная библиотека: интеграция информационных ресурсов: [сборник научных трудов] / Президент. 6-ка им. Б.Н. Ельцина. Вып. 1. - Санкт-Петербург: ФГБУ «Президентская библиотека имени Б. Н. Ельцина», 2011. - 191, [3] с.: ил. - С. 36-46.

6. Ершов, М.Ф. Социокультурная эволюция отечественной провинции конца XVIII - начала XX в.: по материалам городов Северного Зауралья / М.Ф. Ершов; 0бско-угорский институт прикладных исследований и разработок. - Ханты-Мансийск: Печатный мир г. Ханты-Мансийск, 2017. - 123 с.: ил., табл.

7. Информационное общество: проблемы становления и закономерности развития [Текст]: монография / [В.Н. Гончаров и др.]; Центр развития научного сотрудничества. - Новосибирск: ЦРНС, 2014. - 183, [3] с.: ил.

8. Копотилов, М.П. Декабристы в Тобольском крае: 1825-1925 / М. Копотилов. - Тобольск: Издание Комиссии Тобольского окрисполкома по ознаменованию столетия со дня восстания декабристов и Общества изучения края при Музее Тобольского Севера, 1925. - 38 с.

9. Маклюэн, М. Галактика Гутенберга [Текст]: становление человека печатающего / М. Маклюэн; пер. И.0. Тюриной. - 2-е изд. - Москва: Гаудеамус; [Б. м.]: Академический Проект, 2013. - 495 с.

10. Пляхотко, А.С. Возможности современной библиотеки в повышении информационной культуры работников правоохранительных органов / А.С. Пляхотко // Интеграция методической (научно-методической) работы и системы повышения квалификации кадров : материалы XX Межд. научно-практ. конф. / Межд. академия наук пед. образования; Челяб. институт перепод. и пов. квал. работ. образ.; отв. ред. Д.Ф. Ильясов. - М.; Челябинск: ЧИППКРО, 2019. -412 с. - С. 71-76.

11. Степин В.С. Цивилизация и культура / В.С. Степин. - СПб.: СПбГУП, 2011. - 408 с.

(c Пляхотко Александр Сергеевич (sanek_tyumen@mail.ru), Акулич Евгений Михайлович (akulich.em@gmail.com).

Журнал «Современная наука: актуальные проблемы теории и практики» 